\title{
Logical Pluralism Hollandaise
}

\author{
Graham Priest \\ Departments of Philosophy \\ Universities of Melbourne and St Andrews \\ g.priest@unimelb.edu.au \\ Received by Hans van Ditmarsch \\ Published December 17, 2008 \\ http://www . philosophy . unimelb.edu.au/ajl/2008 \\ (C) 2008 Graham Priest
}

Johan van Benthem (2008) compares and contrasts two research programmes, which he calls logical pluralism and logical dynamics, stating his 'preference' (p.25) for the second of these 'alternatives' (p. 8). In this note I want to put the matter into a slightly different perspective.

Logical dynamics is the study of the way that rational agents process information, obtained by various sources-observation, testimony, inference-and use it to act and interact. The formal underpinnings of such investigations are provided by versions of dynamic logic. Johan reports some resistance to this project by his Dutch colleagues_-or at least to calling such a project logic. $\mathrm{He}$ would certainly have no such resistance from those of us in New Holland. (I speak for myself here, but I am confident that the attitude is one shared by my own colleagues: I suspect that New Hollanders are much more laid back about these things than Hollanders.) Who cares whether one calls it logic, or by some fancy other name? The question is: is it an interesting project to which those trained in the techniques of contemporary logic can contribute? The answer is clearly yes. No problem.

What Johan calls logical pluralism is rather different from what many selfascribed logical pluralist ${ }^{2}$ call by that name. For him, logical pluralism is the study of sub-structural logics-logics obtained, generally speaking, by taking a sequent calculus for classical logic, and then modifying or eliminating some of its structural rules, such as Weakening and Contraction. That, of course is a perfectly fine enterprise too. But logical pluralism in the more usual sense is both broader and narrower than that. Broader: there are many interesting logics different from classical logic, and not all of these can be thought of as sub-structural-at least, not without a lot torturing. For example, there is a

\footnotetext{
${ }^{I}$ The original name for what is now called Australia. I extend it to New Zealand by fiat.

${ }^{2}$ E.g., Batens (1985), (1990), Beall and Restall (2006), da Costa (1997).
} 
vast variety of paraconsistent logics 3 One family of these, relevant logicsa favourite topic of many New Holland logicians-is a sort of substructural logic ${ }^{4}$ But many of them (such as the non-adjunctive, non-truth-function, and many-valued ones) are not. Narrower: logical pluralism is not just a doctrine to the effect that there is a plurality of interesting logics, but also includes the claim that there is no one of them which is uniquely correct. There is no "one true logic" 5 Typically, different sorts logics are appropriate for different sorts of reasoning contexts.

Why do I emphasize this? After all, I have no objection to Johan using the words 'logical pluralism' as he does if he wants to. I emphasize it because I don't think that Johan take the other sense of logical pluralism as seriously as he should - even by his own lights. The dynamical systems that Johan gives are all ones based on classical logic. (Substructural phenomena are to be " "deconstruct[ed]" into classical logic plus an explicit account of the relevant informational events' (p. I).) Now it would seem clear that for a number of the applications that Johan has in mind, using a non-classical logic would be much more appropriate (whether or not one is a logical pluralist about the matter).

Let me illustrate with respect to Johan's own examples. In any logic with a world-semantics, the consequence relation is defined in terms of truthpreservation over a set of worlds ${ }^{6}$ The class of worlds therefore defines the logic. In Johan's dynamic logics, the worlds are the "possible" worlds of classical modal logic, and so the underlying propositional logic is classical. But all of Johan's constructions can performed with profit with a wider class of worldsclassically "impossible" worlds (be they intuitionist, many-valued, inconsistent, or whatever), making the underlying proportional logic non-classical.

Take, for example, the dynamic epistemic logic in his Section 3. Epistemic possibility is, as most agree, quite different from logical possibility/7 In particular, things may be epistemically possible for a rational agent, even though they are logically impossible. Thus, until the Wiles proof, mathematicians took it to be (epistemically) possible that Fermat's Last Theorem was true, and (epistemically) possible that it was false. If we are to analyse knowledge using worlds, there must, then, be worlds where each alternative holds. And one of these is logically impossible. Moreover, what Wiles proof did was to cut down the space of epistemic possibilities to exclude those in which Fermat's Last Theorem fails-just as Johan describes.

\footnotetext{
${ }^{3}$ For the variety of paraconsistent logics see Priest (2002).

${ }^{4}$ Some care needs to be taken here. Johan puts relevant logics in the family of non-monotonic logic. In one sense this is correct; in another it is not. In the sequent calculi for relevant logics, there are two ways of combining premises, an extensional one, and an intensional one. Weakening fails for intentional combination, but holds extensional combination. See Restall (2000). Thus, in relevant logics as normally conceived, if $\Sigma \vDash A$ then $\Sigma \cup\{B\} \vDash A$; the failure of this is normally taken to be the mark of a non-monotonic logic.

5This is not, incidentally, a view that I, myself, share. See Priest (2006), ch. I2.

${ }^{6}$ See Priest (2008), Part I.

${ }^{7}$ And metaphysical possibility too, but let us not go into these murky waters.
} 
What is true for knowledge is true in spades for belief; so similar considerations apply to Johan's examples of dynamic doxastic and belief-revision logic in Section 4. Even rational agents can have logically false beliefs: very strong evidence can point the wrong way. I think that most logicians will have thought at some time that they had proved a logico-mathematical result, only to find out that there was a loophole in the "proof", and that there were counter-examples to the "theorem". So if belief is to be given a worlds-analysis, we need logically impossible worlds.

Not only can rational people believe things that are logically false, they can not believe or know things that are logically true. Hence, there must also be worlds where logical truths fail. Because there are no such worlds in standard doxastic and epistemic logics, including the dynamic versions constructed by Johan, these are beset with the thorny problem of "logical omniscience" (if $\vDash A$ then $\vDash \square$ A, where $\square$ is an epistemic or doxastic operator).

As for belief-revision, any account of the dynamics of this had better be based on some sort of paraconsistent logic. This is because people, even highly rational people, are wont to have inconsistent beliefs. We need an account of belief-change in which change takes us from one belief state to another, both of which are liable to be inconsistent (but non-trivial). So some sort of paraconsistent apparatus is required $]^{8}$

Anyway, as far as Johan's particular constructions go, I emphasize that, with one exception, the non-classical versions can proceed in exactly the same way as in the classical versions: the truth conditions for the doxastic and epistemic operators, the preference ordering, and the operations on it, etc., can all be as he gives them. The exception is the class of worlds involved, and so the underlying propositional logic. Of course, how best to take such worlds to behave, and so which non-classical logic to employ, is a matter for substantial work. The world-semantics of relevant logic provides what is required in many cases: in these, every statement holds at some worlds, and every statement fails at some worlds. But whether this is the best machinery to use is another matter? 9

It might be suggested that, in all the cases mentioned, the theory is of an ideally rational agent, who never countenances or believes contradictions or other logical impossibilities. Such idealizations have a point. But in the end, if you have a theory that applies only to God (who, being eternally omniscient, hardly has need of a mechanism for belief change or information processing), it is not of much use. We need theories to tell $u$ s how best to handle these matters-what is the rational thing to do, for example, if a person finds out that their beliefs are inconsistent?

\footnotetext{
${ }^{8}$ For an account of belief-change based on a paraconsistent logic, see Priest (2006), ch. 8 .

${ }^{9}$ The machinery of relevant logic is deployed in the account of intentional operators in Priest (2005).
} 
These particular examples makes the point about the usefulness of nonclassical logics for Johan's project. But the point is reinforced by stepping back and looking at the bigger picture. The core of the project is the intelligent management and application of information. But the information with which we operate is always liable to be inconsistent-unless it comes from God. And there is no effective test for inconsistency to filter it out. Inconsistency, then, had better not imply triviality, or there could be no sensible use of such information. Some paraconsistent mechanism must get in on the act.

Indeed, many of the preceding examples invoke paraconsistent logic and its machinery in one way or another. (We in New Holland have had our own issues with conservative Northern colleagues about that topic!) Johan appears to cite paraconsistency as a rival to logical dynamics (p. 26). As should now be clear, this is not at all the case: the tools of paraconsistent logic are just what one needs to pursue a number of applications of logical dynamics effectively.

Paraconsistent logic is just one kind of non-classical logic, of course. Applications of logical dynamics of a kind different from those already noted may well benefit from the use of other non-classical logics-indeed, will do, if logical pluralists of the usual stripe are right. Johan says, referring to his own programme (p. 27), 'I myself see much of our current discussion as trying to break away from the magnetic spell of those mind grooves formed in the grand foundational period of the I930s'. Indeed so. And arguably the biggest magnetic spell of all is the one cast by classical logic.

\section{REFERENCES}

[I] Batens, D. (I985), 'Meaning, Acceptance and Dialectics', in J. C. PItT (ed.), Change and Progress in Modern Science, Dordrecht: Reidel.

[2] вatens, D. (1990), 'Against Global Paraconsistency', Studies in Soviet Thought, 39: 209-29.

[3] Beall, JC, and restall, G. (2006), Logical Pluralism, Oxford: Oxford University Press.

[4] van benthem, J. (2008), 'Logical Pluralism meets Dynamic Logic', Australasian fournal of Logic, forthcoming.

[5] DA CosTA, N. C. A. (1997), Logique Classique et Non-Classique: Essai sur les Fondements de la Logique, Paris: Masson.

[6] Priest, G. (2002) 'Paraconsistent Logic', pp. 287-93, vol. 6, of D. GABBAY and F. GUenthner (eds.), Handbook of Philosophical Logic, and edn, Dordrecht: Kluwer Academic.

[7] PRI est, G. (2005), Towards Non-Being, Oxford: Oxford University Press. 
[8] Priest, G. (2006), Doubt Truth to be a Liar, Oxford: Oxford University Press.

[9] PRI E ST, G. (2008), Introduction to Non-Classical Logic, 2nd edn, Cambridge: Cambridge University Press.

[io] Restall, G. (2000), Introduction to Substructural Logic, London: Routledge. 
The Australasian fournal of Logic (ISSN I448-5052) disseminates articles that significantly advance the study of logic, in its mathematical, philosophical or computational guises. The scope of the journal includes all areas of logic, both pure and applied to topics in philosophy, mathematics, computation, linguistics and the other sciences.

Articles appearing in the journal have been carefully and critically refereed under the responsibility of members of the Editorial Board. Only papers judged to be both significant and excellent are accepted for publication.

The journal is freely available at the journal website at

$$
\text { http://www.philosophy.unimelb.edu.au/ajl/ }
$$

All issues of the journal are archived electronically at the journal website.

SUBSCRIPTIONS Individuals may subscribe to the journal by sending an email, including a full name, an institutional affiliation and an email address to the managing editor at ajl-editors@unimelb.edu.au Subscribers will receive email abstracts of accepted papers to an address of their choice. For institutional subscription, please email the managing editor at ajl-editors@unimelb.edu.au

Complete published papers may be downloaded at the journal's website at http: //www.philosophy.unimelb.edu.au/ajl/ The journal currently publishes in pdf format.

SUBMISSION The journal accepts submissions of papers electronically. To submit an article for publication, send the $\mathrm{HT}_{\mathrm{E}} \mathrm{X}$ source of a submission to a member of the editorial board. For a current list of the editorial board, consult the website.

The copyright of each article remains with the author or authors of that article. 